\title{
Selection of Vendor Based on Intuitionistic Fuzzy Analytical Hierarchy Process
}

\author{
Prabjot Kaur \\ Department of Mathematics, Birla Institute of Technology, Mesra, Ranchi, Jharkhand 835215, India \\ Correspondence should be addressed to Prabjot Kaur; tinderbox_fuzzy@yahoo.com
}

Received 9 July 2014; Revised 10 November 2014; Accepted 11 November 2014; Published 10 December 2014

Academic Editor: Viliam Makis

Copyright (C) 2014 Prabjot Kaur. This is an open access article distributed under the Creative Commons Attribution License, which permits unrestricted use, distribution, and reproduction in any medium, provided the original work is properly cited.

\begin{abstract}
Business environment is characterized by greater domestic and international competitive position in the global market. Vendors play a key role in achieving the so-called corporate competition. It is not easy however to identify good vendors because evaluation is based on multiple criteria. In practice, for VSP most of the input information about the criteria is not known precisely. Intuitionistic fuzzy set is an extension of the classical fuzzy set theory (FST), which is a suitable way to deal with impreciseness. In other words, the application of intuitionistic fuzzy sets instead of fuzzy sets means the introduction of another degree of freedom called nonmembership function into the set description. In this paper, we proposed a triangular intuitionistic fuzzy number based approach for the vendor selection problem using analytical hierarchy process. The crisp data of the vendors is represented in the form of triangular intuitionistic fuzzy numbers. By applying AHP which involves decomposition, pairwise comparison, and deriving priorities for the various levels of the hierarchy, an overall crisp priority is obtained for ranking the best vendor. A numerical example illustrates our method. Lastly a sensitivity analysis is performed to find the most critical criterion on the basis of which vendor is selected.
\end{abstract}

\section{Introduction}

In most industries the cost of raw materials and component parts constitutes the main cost of a product, such that in some cases it can account for up to 70\% (Ghobadian and Stainer [1]). In high technology firms, purchased materials and services represent up to $80 \%$ of total product cost (Weber et al. [2]). Thus the purchasing department can play a key role in an organization's efficiency and effectiveness since the department has a direct effect on cost reduction, profitability, and flexibility of a company by selecting the right suppliers which significantly reduces the purchasing costs and improves corporate competitiveness (Ghodsypour and O'Brien [3]). The objective of supplier selection is to identify suitable supplier on the basis of comparison of suppliers using a common set of criteria and measures.

The first study on vendor selection was carried by Dickson [4] who identified 23 important evaluation criteria for supplier selection. Later Weber et al. reviewed, classified, and addressed the supplier selection problem and
De Boer et al. [5] identified four stages for supplier selection including definition of the problem, formulation of criteria, qualification, and final selection, respectively. A number of methodologies have been proposed for solving vendor selection problem. Some adopted models specifically account for the imprecision of the rating mechanism. We will consider analytical hierarchy process for vendor selection problem. Narsimhan [6] used an analytical hierarchy process to select vendors for general industrial purchasing.Ghodsypour and O'Brien [7] combined AHP and LP in order to take into account tangible and intangible criteria and to optimize order allocation among suppliers. Yahya and Kingsman [8] used Saaty's analytic hierarchy process method into vendor rating system for a government sponsored entrepreneur development programme by describing a case study. Tam and Tummala [9] presented a real case study to select the best vendor for telecommunication systems by formulating analytic hierarchy process (AHP) based approach. It is seen that this approach is flexible and less time consuming. Zhang et al. [10] formulated AHP based model and presented a case 
study to examine the function of 3PL vendor selection of $4 \mathrm{PL}$ systems. This approach shows that computed quantitative evaluations can be applied to improve the precision of the vendor selection. Nydick and Hill [11], Barbarosoglu and Yazgac [12], Bevilacqua and Braglia [13], Tam and Tummala [9], Chan [14], and Sevkli et al. [15] propose the use of analytical hierarchy process to deal with imprecision in supplier choice. AHP has the advantages of simplicity and ease of use, but it does not take into account the uncertainty associated with the mapping of one's perception to a number (Deng [16]). Also conventional AHP is criticized forits inability to handle the uncertainty and imprecision in the pairwise comparison process. Therefore fuzzy AHP was designed to overcome the problem of uncertainty, imprecision, and multiplicity of meaning in hierarchical fuzzy problem. van Laarhoven and Pedrycz [17] were the first to discuss such a procedure by using triangular membership functions and comparing the fuzzy ratios. In a while, Buckley [18] showed how to derive the priorities from a set of fuzzy comparisons described by trapezoidal membership functions. Chang [19] introduced a novel methodology based on the synthetic extent values of the fuzzy pairwise comparisons. Then Mikhailov [20] introduced the method of deriving priorities from fuzzy preference programming. Practical applications of the fuzzy AHP methodology abound. The technique was successfully applied for evaluating the vendors by Morlacchi [21], Kahraman et al. [22], and Chan and Kumar [23]. The best condition for a decision making problem may still not be satisfied when decision situation involves fuzzy or crisp data. In fuzzy set theory, there is no means to incorporate the lack of knowledge with the membership degrees. A possible solution is to use intuitionistic fuzzy sets (IFSs for short), introduced by Atanassov [24]. It is characterized by two functions expressing the degree of membership and the degree of nonmembership, respectively. The theory of the IF set has been found to be more useful to deal with vagueness and uncertainty in decision situations than that of the fuzzy set. A very few approaches of vendor selection problem have been studied under intuitionistic fuzzy set approach. Shahrokhi et al. [25] gave an integrated method using intuitionistic fuzzy set and linear programming for supplier selection problem. Boran et al. [26] gave a multicriteria intuitionistic fuzzy group decision making for supplier selection with TOPSIS method. Chamodrakas et al. [27] evaluated method involving two stages: initial screening of the suppliers through the enforcement of hard constraints on the selection criteria and final supplier evaluation through the application of a modified variant of the Fuzzy Preference Programming (FPP) method. Babić and Perić [28] solve vendor selection problem using an integration of analytic hierarchy process (AHP), weighted sum model (WSM), and fuzzy multiobjective mixed-integer programming to define the optimum quantities among the selected suppliers. The use of IF-AHP can help a decision maker to make more realistic and informed decisions based on available information, without making strong assumptions about the state of knowledge [29]. The combination of IFS and AHP is new in vendor selection problem and handles vagueness and ambiguity uncertainties in AHP involving degree of satisfiability and
TABLE 1: Vendor selection criteria.

\begin{tabular}{ll}
\hline Criterion & Factor \\
\hline Cost (C) & (i) Price \\
& (ii) Logistic costs \\
& (iii) Operating costs \\
& (iv) After-sales service costs \\
\hline & (i) Quality performance \\
& (ii) Marketability \\
(iii) Durability \\
(Q) \\
(iv) Ergonomic qualities \\
(v) Flexibility of operation \\
(vi) Simplicity of operation \\
(vii) Reliability \\
(i) Speed to market \\
(ii) Delivery lead time \\
(iii) Development speed \\
(iv) On-time delivery \\
(C) \\
(v) Fill rate \\
(i) Reaction to demand \\
(ii) Ability to modify product \\
(iii) Supply variety \\
(iv) Technical support \\
(v) After-sales services (e.g., warranties \\
and claim policies) \\
(vi) Flexibility (payment, Freight \\
reduction, order frequency, and amount) \\
(vii) Delivery frequency \\
\hline (i) Position in the industry \\
(ii) Dependability \\
(iii) Trust \\
(iv) Business references \\
(v) Financial condition \\
\end{tabular}

TABLE 2: Crisp data sets for the main comparison matrix.

\begin{tabular}{lccccc}
\hline Goal & C & Q & S & CT & R \\
\hline C & 1 & 1 & 1 & 4 & 1 \\
Q & 1 & 1 & 2 & 4 & 2 \\
S & .25 & .25 & .2 & 1 & .33 \\
CT & 1 & .5 & 1 & 5 & 3 \\
R & 1 & 1 & .33 & 3 & 1 \\
\hline
\end{tabular}

of nonsatisfiability of each vendor with respect to a set of criteria.

The organization of the paper is as follows: Section 1 introduces the vendor selection problem along with the literature view of the problem. Section 2 gives an insight into some basic definitions on intuitionistic fuzzy sets. Section 3 explains the methodology followed by numerical example in 
TABLE 3: Comparison matrix of cost with respect to the three alternatives.

\begin{tabular}{lccc}
\hline Cost & Vendor A & Vendor B & Vendor C \\
\hline Vendor A & 1 & .25 & .5 \\
Vendor B & 4 & 1 & 3 \\
Vendor C & 2 & .33 & 1 \\
\hline
\end{tabular}

TABLE 4: Comparison matrix of quality with respect to the three alternatives.

\begin{tabular}{lccc}
\hline Quality & Vendor A & Vendor B & Vendor C \\
\hline Vendor A & 1 & .25 & .2 \\
Vendor B & 4 & 1 & .5 \\
Vendor C & 5 & 2 & 1 \\
\hline
\end{tabular}

TABle 5: Comparison matrix of service with respect to the three alternatives.

\begin{tabular}{lccc}
\hline Service & Vendor A & Vendor B & Vendor C \\
\hline Vendor A & 1 & .33 & 5 \\
Vendor B & 3 & 1 & 7 \\
Vendor C & .2 & .143 & 1 \\
\hline
\end{tabular}

TABLE 6: Comparison matrix of cycle time with respect to the three alternatives.

\begin{tabular}{lccc}
\hline Cycle time & Vendor A & Vendor B & Vendor C \\
\hline Vendor A & 1 & 3 & 3 \\
Vendor B & .33 & 1 & 1 \\
Vendor C & .33 & 1 & 1 \\
\hline
\end{tabular}

TABLE 7: Comparison matrix of reputation with respect to the three alternatives.

\begin{tabular}{lccc}
\hline Reputation & Vendor A & Vendor B & Vendor C \\
\hline Vendor A & 1 & 1 & 7 \\
Vendor B & 1 & 1 & 7 \\
Vendor C & .143 & .143 & 1 \\
\hline
\end{tabular}

Section 4 and sensitivity analysis in Section 5. Section 6 deals with discussion followed by managerial implications. Finally Section 7 concludes the paper.

\section{Preliminaries on Intuitionistic Fuzzy Sets}

2.1. Definition 1. Given a fixed set $X=\left\{x_{1}, x_{2}, \ldots, x_{n}\right\}$, an intuitionistic fuzzy set (IFS) is defined as $\overline{\bar{A}}=\left(\left\langle x_{i}\right.\right.$, $\left.\left.t_{A}\left(x_{i}\right), f_{A}\left(x_{i}\right)\right\rangle / x_{i} \in X\right)$ which assigns to each element $x_{i}$ a membership degree $t_{A}\left(x_{i}\right)$ and a nonmembership degree $f_{A}\left(x_{i}\right)$ under the condition $0 \leq t_{A}\left(x_{i}\right)+f_{A}\left(x_{i}\right) \leq 1$, for all $x_{i} \in X$.
2.2. Definition 2. A triangular intuitionistic fuzzy number (TIFN) $\overline{\bar{A}}$ is an intuitionistic fuzzy set in $R$ with the following membership function $\mu_{\overline{\bar{A}}}(x)$ and nonmembership $\vartheta_{\overline{\bar{A}}}(x)$ :

$$
\begin{gathered}
\mu_{\overline{\bar{A}}}(x)= \begin{cases}\frac{x-a_{1}}{a_{2}-a_{1}}, & a_{1} \leq x \leq a_{2}, \\
\frac{x-a_{2}}{a_{3}-a_{2}}, & a_{2} \leq x \leq a_{3}, \\
0, & \text { otherwise, }\end{cases} \\
\vartheta_{\overline{\bar{A}}}(x)= \begin{cases}\frac{a_{2}-x}{a_{2}-a_{1}^{\prime}}, & a_{1}^{\prime} \leq x \leq a_{2}, \\
\frac{x-a_{2}}{a_{3}-a_{2}^{\prime}}, & a_{2} \leq x \leq a_{3}^{\prime}, \\
0, & \text { otherwise }\end{cases}
\end{gathered}
$$

where $a_{1}^{\prime} \leq a_{1} \leq a_{2} \leq a_{3} \leq a_{3}^{\prime}$ and $\mu_{\overline{\bar{A}}}+\vartheta_{\overline{\bar{A}}} \leq 1$.

2.3. Arithmetic Operations of Triangular Intuitionistic Fuzzy Number. If $\overline{\bar{A}}=\left\{\left(a_{1}, a_{2}, a_{3}\right) ;\left(a_{1}^{\prime}, a_{2}, a_{3}^{\prime}\right)\right\}$ and $\overline{\bar{B}}=\left\{\left(b_{1}, b_{2}\right.\right.$, $\left.\left.b_{3}\right)\left(b_{1}^{\prime}, b_{2}, b_{3}^{\prime}\right)\right\}$ are two TIFNs, Then we define the following.

(1) Addition of two TIFNs

$$
\begin{aligned}
\overline{\bar{A}} & +\overline{\bar{B}} \\
& =\left\{\left(a_{1}+b_{1}, a_{2}+b_{2}, a_{3}+b_{3}\right)\left(a_{1}^{\prime}+b_{1}^{\prime}, a_{2}+b_{2}, a_{3}^{\prime}+b_{3}^{\prime}\right)\right\}
\end{aligned}
$$

is also a TIFN.

(2) Subtraction of two TIFNs

$$
\begin{aligned}
\overline{\bar{A}} & -\overline{\bar{B}} \\
& =\left\{\left(a_{1}-b_{3}, a_{2}-b_{2}, a_{3}-b_{1}\right)\left(a_{1}^{\prime}-b_{3}^{\prime}, a_{2}-b_{2}, a_{3}^{\prime}-b_{1}^{\prime}\right)\right\}
\end{aligned}
$$

is also a TIFN.

(3) Multiplication of two TIFNs

$$
\overline{\bar{A}} \times \overline{\bar{B}}=\left\{\left(a_{1} b_{1}, a_{2} b_{2}, a_{3} b_{3}\right)\left(a_{1}^{\prime} b_{1}^{\prime}, a_{2} b_{2}, a_{3}^{\prime} b_{3}^{\prime}\right)\right\}
$$

is also a TIFN.

(4) If TIFN $\overline{\bar{A}}=\left(a_{1}, a_{2}, a_{3}\right)\left(a_{1}^{\prime}, a_{2}, a_{3}^{\prime}\right)$ and $y=k a$ (with $k>0)$, then

$\overline{\bar{y}}^{\prime}=k \overline{\bar{A}}^{\prime}$ is a TIFN $\left\{\left(k a_{1}, k a_{2}, k a_{3}\right)\left(k a_{1}^{\prime}, k a_{2}, k a_{3}^{\prime}\right)\right\}$.

(5) Division of two TIFNs

$$
\frac{\overline{\bar{A}}}{\overline{\bar{B}}}=\left\{\left(\frac{a_{1}}{b_{3}}, \frac{a_{2}}{b_{2}}, \frac{a_{3}}{b_{1}}\right)\left(\frac{a_{1}^{\prime}}{b_{3}^{\prime}}, \frac{a_{2}}{b_{2}}, \frac{a_{3}^{\prime}}{b_{1}^{\prime}}\right)\right\}
$$

is also a TIFN. 
TABLE 8: Intuitionistic fuzzy pairwise comparison of the main criteria.

\begin{tabular}{lccccc}
\hline Goal & $\mathrm{C}$ & $\mathrm{Q}$ & $\mathrm{S}$ & $\mathrm{CT}$ & $\mathrm{R}$ \\
\hline $\mathrm{C}$ & $(.8,1,2)(.5,1,2.1)$ & $(.8,1,2)(.5,1,2.1)$ & $(.8,1,2)(.5,1,2.1)$ & $(3,4,5)(2.5,4,5.2)$ & $(.8,1,2)(.5,1,2.1)$ \\
$\mathrm{Q}$ & $(.8,1,2)(.5,1,2.1)$ & $(.8,1,2)(.5,1,2.1)$ & $(1,2,2.5)(.85,2,2.7)$ & $(3,4,5)(2.5,4,5.2)$ & $(1,2,2.5)(.85,2,2.7)$ \\
$\mathrm{S}$ & $(.1, .25, .9)(.08, .25,1)$ & $(.1, .25, .9)(.08, .25,1)$ & $(.8,1,2)(.5,1,2.1)$ & $(4,5,6)(3.5,6,6.1)$ & $(.15, .33,1)(.1, .33,1.1)$ \\
$\mathrm{CT}$ & $(.8,1,2)(.5,1,2.1)$ & $(.8,1,2)(.5,1,2.1)$ & $(.15, .33,1)(.1, .33,1.1)$ & $(.8,1,2)(.5,1,2.1)$ & $(.15, .33,1)(.1, .33,1.1)$ \\
$\mathrm{R}$ & $(.8,1,2)(.5,1,2.1)$ & $(.8,1,2)(.5,1,2.1)$ & $(.15, .33,1)(.1, .33,1.1)$ & $(2,3,4)(1.5,3,4.1)$ & $(.8,1,2)(.5,1,2.1)$ \\
\hline
\end{tabular}

TABLE 9: Intuitionistic fuzzy pairwise comparison for the vendors under cost.

\begin{tabular}{lccr}
\hline Cost & Vendor A & Vendor B & Vendor C \\
\hline Vendor A & $(.8,1,2)(.5,1,2.1)$ & $(.1, .25, .9)(.08, .25,1)$ & $(.2, .55,1)(.15, .55,1.5)$ \\
Vendor B & $(3,4,5)(2.5,4,5.2)$ & $(.8,1,2)(.5,1,2.1)$ & $(2,3,4)(1.5,3,4.1)$ \\
Vendor C & $(1,2,2.5)(.85,2,2.7)$ & $(.8,1,2)(.5,1,2.1)$ & $(.8,1,2)(.5,1,2.1)$ \\
\hline
\end{tabular}

2.4. Proposed Accuracy Function for Defuzzification. Let $\overline{\bar{A}}=$ $\left\{\left(a_{1}, a_{2}, a_{3}\right) ;\left(a_{1}^{\prime}, a_{2}, a_{3}^{\prime}\right)\right\}$ be a TIFN; then accuracy function [30] for defuzzification is defined as

$$
\overline{\bar{A}}^{\prime}=\frac{\left(a_{1}+2 a_{2}+a_{3}\right)+\left(a_{1}^{\prime}+2 a_{2}+a_{3}^{\prime}\right)}{8} .
$$

2.5. Intuitionistic Analytical Hierarchy Process. The AHP is propounded by Saaty [31] and afterwards gained acceptance for selection phase of decision making process. In intuitionistic fuzzy AHP the pairwise comparison matrix is represented as triangular intuitionistic fuzzy numbers. The weights for the priorities are computed using simple arithmetic operations of triangular intuitionistic fuzzy numbers.

A step-by-step procedure for the intuitionistic fuzzy analytic hierarchy (IF-AHP) is provided in the algorithm below. To develop IF-AHP an example for vendor selection problem [32] is provided.

This section presents an algorithm for intuitionistic fuzzy AHP and pairwise comparison scale in evaluation. The algorithm of IF-AHP is presented as follows.

\section{Methodology}

Step 1. The AHP decision problem is structured hierarchically at different levels. The top level of the hierarchy represents the overall goal, while the lowest level is composed of all possible alternatives. One or more intermediate levels represent the decision criteria and subcriteria (Figure 1).

Step 2. Develop intuitionistic fuzzy judgement comparisons matrix $\overline{\bar{A}}$. Intuitionistic fuzzy judgment matrix $\overline{\bar{A}}$ is generated using pairwise comparisons during evaluation. The vagueness of decision makers is represented by triangular intuitionistic fuzzy numbers $\left(\overline{\overline{a_{i j}}}\right)$. The triangular fuzzy number is represented as triplets $\overline{\overline{a_{i j}}}=\left(l_{i j}, m_{i j}, n_{i j}\right)\left(l_{i j}^{\prime}, m_{i j}, n_{i j}^{\prime}\right)$.

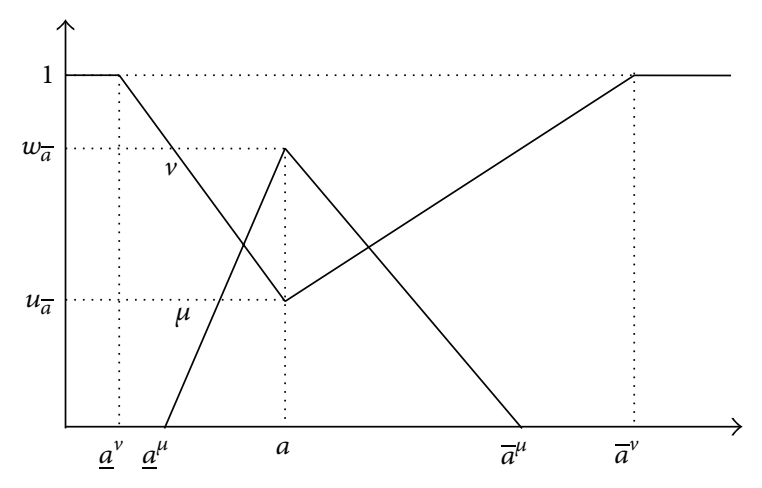

FIGURE 1: Triangular intuitionistic fuzzy number (TIFN).

Such notation will be used in our further exposition. Then construct the fuzzy pairwise comparison such that

$$
\overline{\bar{A}}=\left[\begin{array}{cccc}
1 & \overline{\bar{a}}_{12} & \cdots & \overline{\bar{a}}_{1 n} \\
\overline{\bar{a}}_{21} & 1 & \cdots & \overline{\bar{a}}_{2 n} \\
\vdots & \vdots & \ddots & \vdots \\
\overline{\bar{a}}_{n 1} & \overline{\bar{a}}_{n 2} & \cdots & 1
\end{array}\right],
$$

where $\overline{\bar{a}}_{j i}=1 / \overline{\bar{a}}_{i j}$.

Step 3. AHP methodology provides a consistency index [31] to measure any inconsistency within the judgments in each comparison matrix as well as for the entire hierarchy. The AHP utilizes consistency index (CI) and consistency ratio (CR) to discern if there is any inconsistency in the fuzzy judgment matrix. The threshold of the CR is less than $10 \%$ for acceptable results.

Step 4. We calculate the intuitionistic fuzzy set priority weights for the hierarchy of subcriteria and alternative with respect to all criteria. The geometric mean method is used to compute the intuitionistic fuzzy priority weights. For each 
TABLE 10: Intuitionistic fuzzy pairwise comparison of quality with respect to the three alternatives.

\begin{tabular}{lccr}
\hline Quality & Vendor A & Vendor B & Vendor C \\
\hline Vendor A & $(.8,1,2)(.5,1,2.1)$ & $(.1, .25, .9)(.05, .25,1)$ & $(.08, .2, .5)(.06, .2, .7)$ \\
Vendor B & $(3,4,5)(2.5,4,5.2)$ & $(.8,1,2)(.5,1,2.1)$ & $(.2, .55,1)(.15, .55,1.5)$ \\
Vendor C & $(4,5,6)(3.5,6,6.1)$ & $(1,2,2.5)(.85,2,2.7)$ & $(.8,1,2)(.5,1,2.1)$ \\
\hline
\end{tabular}

TABLE 11: Intuitionistic fuzzy pairwise comparison of service with respect to the three alternatives.

\begin{tabular}{lccc}
\hline Service & Vendor A & Vendor B & Vendor C \\
\hline Vendor A & $(.8,1,2)(.5,1,2.1)$ & $(.15, .33,1)(.1, .33,1.1)$ & $(4,5,6)(3.5,5,6.1)$ \\
Vendor B & $(2,3,4)(1.5,3,4.1)$ & $(.8,1,2)(.5,1,2.1)$ & $(6,7,8)(6,7,8.2)$ \\
Vendor C & $(.08, .2, .5)(.06, .2, .7)$ & $(.1, .14, .5)(.05, .14, .65)$ & $(.8,1,2)(.5,1,2.1)$ \\
\hline
\end{tabular}

row geometric mean $\overline{\overline{P_{i}}}$ is determined using the following formula:

$$
\overline{\overline{P_{i}}}=\left(\overline{\overline{P_{i 1}}} \otimes \cdots \otimes \overline{\overline{P_{i n}}}\right)^{1 / n}
$$

Intuitionistic fuzzy weight after normalization is given by

$$
\overline{\overline{w_{i}}}=\overline{\overline{P_{i}}} \otimes\left(\overline{\overline{P_{1}}} \oplus \cdots \oplus \overline{\overline{P_{n}}}\right)^{-1}
$$

Step 5. This includes aggregating the local priorities to get global priorities.

Step 6. Establish hierarchical layer sequencing for determining global priorities. The weighted intuitionistic fuzzy performance for each alternative on each criteria is evaluated.

In this step multiplication intuitionistic fuzzy triangular numbers are used for getting the weighted intuitionistic fuzzy decision matrix (see Table 23).

Step 7. This step includes defuzzification and ranking of vendors.

Ranking of alternative is as follows.

(1) Average score of alternatives with respect to criteria:

$$
S\left(A_{i}\right)=\sum_{j=1}^{m} A_{i}\left(C_{j}\right) .
$$

(2) Defuzzification of average of alternatives:

$$
D\left\{S\left(A_{i}\right)\right\}=\left[\frac{\left(a_{1}+2 a_{2}+a_{3}\right)+\left(a_{1}^{\prime}+2 a_{2}+a_{3}^{\prime}\right)}{8}\right] .
$$

\section{Numerical Example}

A high technology manufacturing company desires to select suitable material vendor to purchase the key components of new products. Three potential vendors $\mathrm{A}, \mathrm{B}$, and $\mathrm{C}$ were shortlisted for evaluation after preliminary screening. The evaluation is based on five criteria (Table 1): (1) cost (C), (2) quality (Q), (3) cycle time (CT), (4) service (S), and (5) reputation $(\mathrm{R})$. The hierarchical structure of this decision problem is shown in Figure 2. The crisp data used for evaluating the vendors is shown in Tables $2,3,4,5,6$, and 7 . The crisp data are converted into triangular fuzzy numbers to construct the fuzzy decision matrix (Tables 8, 9, 10, 11, 12, and 13) and determine the fuzzy weight of each criterion (Tables $14,15,16,17,18$, and 19).

\subsection{Algorithm}

Step 1. Formulate the decision problem as a hierarchical structure (Figure 2). The first layer represents the goal of the problem, the second layer represents important decision criteria, and the third layer represents the alternative choices.

Step 2. Determine the fuzzy comparison judgment matrix by using intuitionistic triangular fuzzy numbers given as follows:

$$
\begin{array}{ll}
\widetilde{1}=(.8,1,2)(.5,1,2.1) & \widetilde{2}=(1,2,2.5)(.85,2,2.7) \\
\widetilde{3}=(2,3,4)(1.5,3,4.1) & \widetilde{4}=(3,4,5)(2.5,4,5.2) \\
\widetilde{5}=(4,5,6)(3.5,6,6.1) & \widetilde{7}=(6,7,8)(6,7,8.2) .
\end{array}
$$

Step 3. Compute local priorities first from pairwise comparison of criteria and then pairwise comparison of vendors with respect to all criteria.

Step 4. Determine the weights of each criterion from the corresponding pairwise criteria comparison matrix for calculating overall priority of membership and nonmembership function of each vendor and final ranking of all vendors (see Table 20).

Step 5. Ranking the vendor with the highest priority score is chosen for allocation of order quantity.

\section{Sensitivity Analysis}

Every proposed model presented by different researchers should be subject to various analyses. Sensitivity analysis is a relationship between input parameter and the output parameter of the model. It is a technique used to determine 
TABLE 12: Intuitionistic fuzzy pairwise comparison matrix of cycle time with respect to the three alternatives.

\begin{tabular}{lccr}
\hline Cycle time & Vendor A & Vendor B & \multicolumn{1}{c}{ Vendor C } \\
\hline Vendor A & $(.8,1,2)(.5,1,2.1)$ & $(2,3,4)(1.5,3,4.1)$ & $(2,3,4)(1.5,3,4.1)$ \\
Vendor B & $(.15, .33,1)(.1, .33,1.1)$ & $(.8,1,2)(.5,1,2.1)$ & $(.8,1,2)(.5,1,2.1)$ \\
Vendor C & $(.15, .33,1)(.1, .33,1.1)$ & $(.8,1,2)(.5,1,2.1)$ & $(.8,1,2)(.5,1,2.1)$ \\
\hline
\end{tabular}

TABLE 13: Intuitionistic fuzzy pairwise comparison of reputation with respect to the three alternatives.

\begin{tabular}{lccc}
\hline Reputation & Vendor A & Vendor B & Vendor C \\
\hline Vendor A & $(.8,1,2)(.5,1,2.1)$ & $(.8,1,2)(.5,1,2.1)$ & $(6,7,8)(6,7,8.2)$ \\
Vendor B & $(.8,1,2)(.5,1,2.1)$ & $(.8,1,2)(.5,1,2.1)$ & $(6.5,7,8)(6,7,8.2)$ \\
Vendor C & $(.1, .14, .5)(.05, .14, .65)$ & $(.1, .14, .5)(.05, .14, .65)$ & $(.8,1,2)(.5,1,2.1)$ \\
\hline
\end{tabular}

TABLE 14: Weights obtained from Table 2.

\begin{tabular}{lc}
\hline Goal & \\
\hline $\mathrm{C}$ & $(1.042,1.31,2.402)(.689,1.31,2.51)$ \\
$\mathrm{Q}$ & $(1.1394,1.74,2.62)(.853,1.74,2.78)$ \\
$\mathrm{S}$ & $(.1572, .33, .95)(.130, .38,1.10)$ \\
$\mathrm{CT}$ & $(1.00,1.52,2.49)(.472,1.146,2.23)$ \\
$\mathrm{R}$ & $(.68, .99,2.00)(.451, .998,2.10)$ \\
\hline
\end{tabular}

TABLE 15: Weights for the vendors under cost from Table 3.

\begin{tabular}{lc}
\hline Cost & \\
\hline Vendor A & $(.255, .519,1.214)(.1898, .519,1.46)$ \\
Vendor B & $(1.67,2.27,3.378)(1.23,2.27,3.50)$ \\
Vendor C & $(.8631,1.25,2.138)(.599,1.25,2.26)$ \\
\hline
\end{tabular}

TABLE 16: Weights for the vendors under quality from Table 4.

\begin{tabular}{ll}
\hline Quality & \\
\hline Vendor A & $(.188, .372, .965)(.136, .372,1.13)$ \\
Vendor B & $(.784,1.29,2.13)(.575,1.29,2.51)$ \\
Vendor C & $(1.467,2.13,3.07)(1.14,2.27,3.21)$ \\
\hline
\end{tabular}

TABLE 17: Weights for the vendors under service from Table 5.

\begin{tabular}{lc}
\hline Service & \\
\hline Vendor A & $(.784,1.179,2.27)(.562,1.252,2.394)$ \\
Vendor B & $(2.16,2.73,3.94)(1.642,2.731,4.0748)$ \\
Vendor C & $(.188, .307, .795)(.117, .307, .9851)$ \\
\hline
\end{tabular}

TABLE 18: Weights for the vendors under cycle time from Table 6.

\begin{tabular}{lc}
\hline Cycle time & \\
\hline Vendor A & $(1.467,2.064,3.138)(1.0396,2.0649,3.2417)$ \\
Vendor B & $(.4615, .6936,1.5801)(.6244, .6936,1.6318)$ \\
Vendor C & $(.4615, .6936,1.5801)(.2960, .6936,1.6318)$ \\
\hline
\end{tabular}

the effect of economic and technical parameters on the profitability of the model.

5.1. Algorithm. Let us consider a decision making problem which consists of $M$ alternatives and $N$ criteria. In this paper
TABLE 19: Weights for the vendors under reputation from Table 7.

\begin{tabular}{lc}
\hline Reputation & \\
\hline Vendor A & $(.7487,1.9006,3.138)(1.1432,1.9006,3.2676)$ \\
Vendor B & $(1.6007,1.9506,3.138)(1.1432,1.9006,3.2676)$ \\
Vendor C & $(.2032, .2732, .795)(.1101, .2732, .9613)$ \\
\hline
\end{tabular}

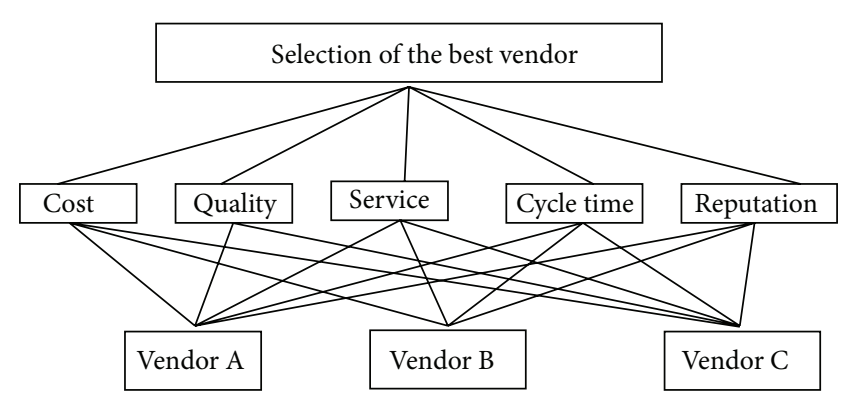

FIGURE 2: AHP model for vendor selection problem.

alternatives are denoted by $A_{i}$ (for $i=1,2,3, \ldots, M$ ) and criteria by $C_{j}$ (for $\left.j=1,2,3, \ldots, N\right)$. Weights of each criterion are given which determines its importance, or weight, $W_{j}$, where

$$
\sum_{j=1}^{n} w_{j}=1
$$

$a_{i j}($ for $i=1,2,3, \ldots, M$ and $j=1,2,3, \ldots, N)$ determines the importance (or measure of performance) of alternative $A_{i}$ in terms of criterion $C_{j}$.

Step 1. Calculate $\delta_{k i j}$ using formula

$$
\delta_{k i j}=\frac{\left(P_{j}-P_{i}\right)}{\left(a_{j k}-a_{i k}\right)}
$$

and calculate $\delta_{k i j}^{\prime}$ using formula

$$
\delta_{k i j}^{\prime}=\frac{\left(P_{j}-P_{i}\right)}{\left(a_{j k}-a_{i k}\right)} \times \frac{100}{W_{k}} .
$$


TABLE 20: Overall priority of membership and nonmembership function of each vendor.

\begin{tabular}{lcccc}
\hline & Criteria weights & Vendor A & Vendor B & Vendor C \\
\hline \multirow{2}{*}{ Cost } & $(1.042,1.31,2.402)$ & $(.255, .519,1.214)$ & $(1.67,2.27,3.378)$ & $(.8631,1.25,2.138)$ \\
& $(.689,1.31,2.5)$ & $(.1898, .519,1.46)$ & $(1.23,2.27,3.50)$ & $(.599,1.25,2.26)$ \\
\hline \multirow{2}{*}{ Quality } & $(1.1394,1.74,2.62)$ & $(.188, .372, .965)$ & $(.784,1.29,2.13)$ & $(.8631,1.25,2.138)$ \\
& $(.853,1.74,2.78)$ & $(.136, .372,1.13)$ & $(.575,1.29,2.51)$ & $(.599,1.25,2.26)$ \\
\hline \multirow{2}{*}{ Service } & $(.1572, .33, .95)$ & $(.784,1.179,2.27)$ & $(2.16,2.73,3.94)$ & $(.188, .307, .795)$ \\
& $(.130, .38,1.10)$ & $(.562,1.252,2.394)$ & $(1.642,2.731,4.0748)$ & $(.117, .307, .9851)$ \\
\hline \multirow{2}{*}{ Cycle time } & $(1.00,1.52,2.49)$ & $(.4615, .6936,1.5801)$ & $(.4615, .6936,1.5801)$ & $(.4615, .6936,1.5801)$ \\
& $(.472,1.146,2.23)$ & $(.2960, .6936,1.6318)$ & $(.6244, .6936,1.6318)$ & $(.2960, .6936,1.6318)$ \\
\hline \multirow{2}{*}{ Reputation } & $(.68, .99,2.00)$ & $(.7487,1.9006,3.138)$ & $(1.6007,1.9506,3.138)$ & $(.2032, .2732, .795)$ \\
& $(.451, .998,2.10)$ & $(1.1432,1.9006,3.2676)$ & $(1.1432,1.9006,3.2676)$ & $(.1101, .2732, .9613)$ \\
\hline
\end{tabular}

TABLE 21: Final weights for vendors.

\begin{tabular}{lccr}
\hline & Vendor A & Vendor B & Vendor C \\
\hline $\mathrm{C}$ & $(.255, .6799,2.916)$ & $(1.67,2.9737,8.114)$ & $(.83631,1.6375,5.1355)$ \\
& $(.1292,1.3027,3.6646)$ & $(.8598,5.6977,8.7850)$ & $(.4187,3.1375,5.6726)$ \\
\hline \multirow{2}{*}{$\mathrm{(}$} & $(.2142, .6473,2.5283)$ & $(.8933,2.2446,5.5806)$ & $(1.6715,3.7062,8.0434)$ \\
& $(.1160, .6473,3.1414)$ & $(.4905,2.2446,6.9778)$ & $(.9724,3.9498,8.9235)$ \\
\hline $\mathrm{S}$ & $(.1232, .3891,2.1565)$ & $(.3396, .9009,3.7430)$ & $(.0296, .1013, .7552)$ \\
& $(.0731, .4758,2.6334)$ & $(.2135,1.0378,4.4814)$ & $(.0152, .1167,1.0538)$ \\
\hline \multirow{2}{*}{$\mathrm{RT}$} & $(1.467,3.1373,7.8136)$ & $(.4615,1.0538,3.9344)$ & $(.4615,1.0538,3.9344)$ \\
& $(.4907,2.3653,7.2274)$ & $(.2947, .7949,3.6389)$ & $(.1397,1.87,3.6389)$ \\
\hline \multirow{2}{*}{ Global weights } & $(.5091,1.8816,6.26)$ & $(1.0880,1.8816,6.276)$ & $(.1382, .2705,1.5900)$ \\
& $(.5155,1.8962,6.8607)$ & $(.5155,1.8962,6.8607)$ & $(.0497, .2727,2.0187)$ \\
\hline Crisp weights & $(2.5685,6.7352,21.67)$ & $(4.4524,9.0546,27.64)$ & $(3.1339,6.7693,19.4585)$ \\
\hline
\end{tabular}

TABLE 22: Overall priority matrix.

\begin{tabular}{lcc}
\hline & Priorities & Ranking \\
\hline Vendor A & 8.6559 & III \\
Vendor B & 13.3327 & I \\
Vendor C & 9.7159 & II \\
\hline
\end{tabular}

TABLE 23: Decision matrix.

\begin{tabular}{lccccc}
\hline \multirow{2}{*}{ Alternative } & $C_{1}$ & $C_{2}$ & $C_{3}$ & $\ldots$ & $C_{N}$ \\
& $W_{1}$ & $W_{2}$ & $W_{3}$ & $\ldots$ & $W_{N}$ \\
\hline$A_{1}$ & $a_{11}$ & $a_{12}$ & $a_{13}$ & $\ldots$ & $a_{1 N}$ \\
$A_{2}$ & $a_{21}$ & $a_{22}$ & $a_{23}$ & $\ldots$ & $a_{2 N}$ \\
$A_{3}$ & $a_{31}$ & $a_{32}$ & $a_{33}$ & $\ldots$ & $a_{3 N}$ \\
$\vdots$ & $\vdots$ & $\vdots$ & $\vdots$ & $\vdots$ & $\vdots$ \\
$A_{M}$ & $a_{M 1}$ & $a_{M 2}$ & $a_{M 3}$ & $\ldots$ & $a_{M N}$ \\
\hline
\end{tabular}

Step 2. Choose the criteria $C_{k}$ which correspond to the smallest $\left|\delta_{k i j}^{\prime}\right|$ value.
Step 3. Calculate the degree of $C_{k}$ denoted by $D_{k}^{\prime}$ :

$$
D_{k}^{\prime}=\min _{1 \leq i<j \leq m}\left\{\left|\delta_{k i j}^{\prime}\right|\right\}, \quad \forall n \geq k \geq 1
$$

Step 4. Calculate the sensitivity coefficient of criteria $C_{k}$ denoted by $\operatorname{sens}\left(C_{k}\right)$ :

$$
\operatorname{sens}\left(C_{k}\right)=\frac{1}{D_{k}^{\prime}}, \quad \forall n \geq k \geq 1 \text {. }
$$

5.2. Numerical Example. Decision matrix for the considered numerical example is calculated (Table 24) from the value presented in Table 21. Converting the value of Table 22 we presented the current final preference value in Table 25. Using formula (15) and formula (16) we have calculated the value of all $\delta_{k i j}$ and $\delta_{k i j}^{\prime}$ which is depicted in Tables 26 and 27. Finally sensitivity coefficient is given of five decision criteria in Table 28. Here it is seen that sensitivity analysis of quality criteria is higher than any other criteria used in our proposed problem definition. So we can say easily that this (quality) criterion is the most sensitive and effective criteria followed by cycle time, reputation, cost, and service, respectively. 
TABle 24: Decision matrix constructed from Table 21.

\begin{tabular}{lccccc}
\hline Alternative & Cost & Criterion & Quality \\
& $(0.23427)$ & $(0.282953)$ & $\begin{array}{c}\text { Service } \\
(0.074072)\end{array}$ & $\begin{array}{c}\text { Cycle time } \\
(0.22192)\end{array}$ & 0.518 \\
Reputation \\
Vendor A & 0.1843 & 0.1293 & 0.3101 & 0.2225 & 0.4629 \\
Vendor B & 0.4513 & 0.345 & 0.5842 & 0.2594 \\
Vendor C & 0.3644 & 0.5257 & 0.1057 & 0.104729 \\
\hline
\end{tabular}

TABLE 25: Current final preference constructed from Table 22.

\begin{tabular}{lcc}
\hline Alternative & Preference $\left(P_{j}\right)$ & Ranking \\
\hline Vendor A & 0.2914 & 3 \\
Vendor B & 0.4096 & 1 \\
Vendor C & 0.2987 & 2 \\
\hline
\end{tabular}

\section{Discussion and Managerial Implications}

Sadiq and Tesfamariam [29]proposed IF-AHP methodology for selecting the best drilling fluid for drilling operations under multiple environmental criteria. The concept of IFS in AHP is introduced through pairwise comparisons. The geometric mean is used to compute the intuitionistic fuzzy weights. The intuitionistic fuzzy weights at each level are aggregated to obtain final ranking orders for the alternatives. In this paper, we proposed an IF-AHP based approach for the vendor selection problem. The concept of IFS was introduced by using triangular intuitionistic fuzzy numbers for pairwise comparison. Our aim was to obtain grade of membership for various criteria under various vendors. The grade of membership should be reliable with respect to the context. The consistency ratio was .007 less than .01, making the purchasers evaluation consistent. By applying AHP various priorities were derived for the various levels of the hierarchy. An overall crisp priority is obtained for ranking the best vendor. Lastly a sensitivity analysis is performed to find the most critical criterion on the basis of which vendor is selected. Sensitivity analysis showed that quality criteria followed by cycle time, reputation, cost, and service are more effective than any other criteria used in our proposed problem.

The vendor selection model developed in this study reveals that it can be put to use for both practitioners and researchers. Managers should focus on a set of supplier selection criteria that evaluates suppliers across various dimensions including product quality, product performance, and delivery reliability. A suitable and well-defined set of criteria helps to improve performances of vendors for customer satisfaction as well as its position in the market place. The model performs the ranking of vendors; it provides a means for purchasing managers to set certain level of comparison for selection of higher rated vendors and elimination of lowerranked vendors. The advantage of this model is that it deals in a categorical, comprehensive, and detailed manner by arranging the vendor selection problem in a hierarchy. A good and efficient management increases the firm's competitive environment.

\section{Conclusions}

Since 1960s, many researchers have contributed their research interest in the field of vendor selection problem. In this paper we presented AHP based approach in vendor selection using triangular intuitionistic fuzzy numbers. AHP based approach can help a decision maker to make more efficient, flexible, and realistic decisions based upon the available criteria and alternatives. To develop the TIFN-AHP methodology properly a step-by-step algorithm with a simple numerical example is illustrated. Fuzzification was done for intuitionistic fuzzy pairwise comparison between criteria. Then intuitionistic fuzzy set of weights was calculated using intuitionistic fuzzy judgment matrix. Establish hierarchical layer sequencing to estimate global weights to obtain final ranking of the vendors. The intuitionistic defuzzification was done for converting the final IF-AHP score into a crisp value for ranking of vendors. Final calculated global weights and corresponding crisp weights are defined in Table 21. From the calculated final crisp weights ranking of alternatives (vendors) was done, which is shown in Table 22. The ranking of vendors is as vendor $B$, vendor $C$, and vendor $A$. This final result shows accuracy in analysis and ranking of alternatives. Also by sensitivity analysis we see that quality followed by cost was the reason behind the selection of the vendor $\mathrm{B}$.

TIFN provides better optimization modeling in uncertain domain for decision maker. Basically AHP model is very much transparent because hierarchical structure in AHP is easy to understand and comparison between various criteria is easy to capture. AHP is useful when one is evaluating the various fields of a particular domain because this is based on criteria and alternatives.

Sensitivity analysis of criteria for vendor selection problem is very complex task. In our research work sensitivity analysis by using various criteria (quality, cycle time, reputation, cost, and service) was presented. From the result of sensitivity analysis we can collect the information about the input parameter of evaluated criteria that will be helpful in decision making of vendor selection problem. And also we 
TABLE 26: All possible $\delta_{k i j}$ values.

\begin{tabular}{|c|c|c|c|c|c|}
\hline \multirow{2}{*}{ Pair of alternatives } & \multicolumn{5}{|c|}{ Criterion } \\
\hline & Cost & Quality & Service & Cycle time & Reputation \\
\hline Vendor A and vendor B & 0.442697 & 0.547983 & 0.431229 & -0.4 & -3.94 \\
\hline Vendor A and vendor C & 0.040533 & 0.018416 & -0.03571 & -0.02823 & -0.02038 \\
\hline Vendor B and vendor C & 1.27618 & 0.613724 & 0.231766 & -3.00542 & 0.337904 \\
\hline
\end{tabular}

TABLE 27: All possible $\delta_{k i j}^{\prime}$ values.

\begin{tabular}{|c|c|c|c|c|c|}
\hline \multirow{2}{*}{ Pair of alternatives } & \multicolumn{5}{|c|}{ Criterion } \\
\hline & Cost & Quality & Service & Cycle time & Reputation \\
\hline Vendor A and vendor B & 188.9686 & 193.6658 & 582.1761 & -180.245 & -2995.9 \\
\hline Vendor $\mathrm{A}$ and vendor $\mathrm{C}$ & 17.30185 & 6.50841 & -48.2156 & -12.7203 & -15.4963 \\
\hline Vendor $B$ and vendor $C$ & 544.7473 & 216.8998 & 312.8928 & -1354.28 & 256.9356 \\
\hline
\end{tabular}

TABLE 28: Sensitivity analysis of criterion.

\begin{tabular}{lcccc}
\hline $\begin{array}{l}\text { Sens. } \\
\text { (cost) }\end{array}$ & $\begin{array}{c}\text { Sens. } \\
\text { (quality) }\end{array}$ & $\begin{array}{c}\text { Sens. } \\
\text { (service) }\end{array}$ & $\begin{array}{c}\text { Sens. } \\
\text { (cycle time) }\end{array}$ & $\begin{array}{c}\text { Sens. } \\
\text { (reputation) }\end{array}$ \\
\hline 0.057797 & 0.153647 & -0.02074 & -0.07861 & -0.06453 \\
\hline
\end{tabular}

will be able to collect the information about the evaluated criteria used in vendor selection problem.

\section{Conflict of Interests}

The author declares that there is no conflict of interests regarding the publication of this paper.

\section{Acknowledgment}

The author would like to thank University Grants Commission (UGC) for funding of this research work under a major research project.

\section{References}

[1] A. Ghobadian and T. Stainer, "A computerized vendor rating system," in Proceedings of the 1st International Symposium on Logistics, pp. 321-328, Nottingham, UK, July 1993.

[2] C. A. Weber, J. R. Current, and W. C. Benton, "Vendor selection criteria and methods," European Journal of Operational Research, vol. 50, no. 1, pp. 2-18, 1991.

[3] S. H. Ghodsypour and C. O'Brien, “The total cost of logistics in supplier selection, under conditions of multiple sourcing, multiple criteria and capacity constraint," International Journal of Production Economics, vol. 73, no. 1, pp. 15-27, 2001.

[4] G. W. Dickson, "An analysis of vendor selection system and decisions," Journal of Purchasing, vol. 2, no. 1, pp. 28-41, 1966.

[5] L. De Boer, E. Labro, and P. Morlacchi, "A review of methods supporting supplier selection," European Journal of Purchasing and Supply Management, vol. 7, no. 2, pp. 75-89, 2001.

[6] R. Narsimhan, "An analytical approach to supplier selection," Journal of Purchasing and Materials Management, pp. 27-32, 1983.
[7] S. H. Ghodsypour and C. O’Brien, "A decision support system for supplier selection using an integrated analytic hierarchy process and linear programming," International Journal of Production Economics, vol. 56-57, pp. 199-212, 1998.

[8] S. Yahya and B. Kingsman, "Vendor rating for an entrepreneur development programme: a case study using the analytic hierarchy process method," Journal of the Operational Research Society, vol. 50, no. 9, pp. 916-930, 1999.

[9] M. C. Y. Tam and V. M. R. Tummala, "An application of the AHP in vendor selection of a telecommunications system," Omega, vol. 29, no. 2, pp. 171-182, 2001.

[10] H. Zhang, X. Li, W. Liu, B. Li, and Z. Zhang, "An application of the AHP in 3PL vendor selection of a $4 \mathrm{PL}$ system," in Proceedings of the IEEE International Conference on Systems, Man and Cybernetics, pp. 1255-1260, October 2004.

[11] R. L. Nydick and R. P. Hill, "Using the analytic hierarchy process to structure the supplier selection procedure," International Journal of Purchasing and Materials Management, vol. 25, no. 2, pp. 31-36, 1992.

[12] G. Barbarosoglu and T. Yazgac, "An application of the analytic hierarchy process to the supplier selection problem," Production and Inventory Management Journal, vol. 38, no. 1, pp. 14-21, 1997.

[13] M. Bevilacqua and M. Braglia, "The analytic hierarchy process applied to maintenance strategy selection," Reliability Engineering and System Safety, vol. 70, no. 1, pp. 71-83, 2000.

[14] F. T. S. Chan, "Interactive selection model for supplier selection process: an analytical hierarchy process approach," International Journal of Production Research, vol. 41, no. 15, pp. 3549-3579, 2003.

[15] M. Sevkli, S. C. L. Koh, S. Zaim, M. Demirbag, and E. Tatoglu, "An application of data envelopment analytic hierarchy process for supplier selection: a case study of BEKO in Turkey," International Journal of Production Research, vol. 45, no. 9, pp. 1973-2003, 2007.

[16] H. Deng, "Multicriteria analysis with fuzzy pairwise comparison," International Journal of Approximate Reasoning, vol. 21, no. 3, pp. 215-231, 1999.

[17] P. J. M. van Laarhoven and W. Pedrycz, "A fuzzy extension of Saaty's priority theory," Fuzzy Sets and Systems, vol. 11, no. 1-3, pp. 199-227, 1983.

[18] J. J. Buckley, "Fuzzy hierarchical analysis," Fuzzy Sets and Systems, vol. 17, no. 3, pp. 233-247, 1985. 
[19] D.-Y. Chang, "Applications of the extent analysis method on fuzzy AHP," European Journal of Operational Research, vol. 95, no. 3, pp. 649-655, 1996.

[20] L. Mikhailov, "Deriving priorities from fuzzy pairwise comparison judgements," Fuzzy Sets and Systems, vol. 134, no. 3, pp. 365385, 2003.

[21] P. Morlacchi, "Vendor evaluation and selection: the design process and a fuzzy hierarchical model," in Proceedings of the 8th IPSERA Conference, 1999.

[22] C. Kahraman, U. Cebeci, and Z. Ulukan, "Multi-criteria supplier selection using fuzzy AHP," Logistics Information Management, vol. 16, pp. 382-394, 2003.

[23] F. T. S. Chan and N. Kumar, "Global supplier development considering risk factors using fuzzy extended AHP-based approach," Omega, vol. 35, no. 4, pp. 417-431, 2007.

[24] K. T. Atanassov, "Intuitionistic fuzzy sets," Fuzzy Sets and Systems, vol. 20, no. 1, pp. 87-96, 1986.

[25] M. Shahrokhi, A. Bernard, and H. Shidpour, "An integrated method using intuitionistic fuzzy set and linear programming for supplier selection problem," in Proceedings of the 18th IFAC World Congress, pp. 6391-6395, Milano, Italy, AugustSeptember 2011.

[26] F. E. Boran, S. Genç, M. Kurt, and D. Akay, "A multi-criteria intuitionistic fuzzy group decision making for supplier selection with TOPSIS method," Expert Systems with Applications, vol. 36, no. 8, pp. 11363-11368, 2009.

[27] I. Chamodrakas, D. Batis, and D. Martakos, "Supplier selection in electronic marketplaces using satisficing and fuzzy AHP," Expert Systems with Applications, vol. 37, no. 1, pp. 490-498, 2010.

[28] Z. Babić and T. Perić, "Multiproduct vendor selection with volume discounts as the fuzzy multi-objective programming problem," International Journal of Production Research, vol. 52, no. 14, pp. 4315-4331, 2014.

[29] R. Sadiq and S. Tesfamariam, "Environmental decision-making under uncertainty using intuitionistic fuzzy analytic hierarchy process (IF-AHP)," Stochastic Environmental Research and Risk Assessment (SERRA), vol. 23, no. 1, pp. 75-91, 2009.

[30] A. Nagoorgani and K. Ponnalagu, "A new approach on solving intuitionistic fuzzy linear programming problem," Applied Mathematical Sciences, vol. 6, no. 69-72, pp. 3467-3474, 2012.

[31] T. L. Saaty, The Analytic Hierarchy Process, McGraw-Hill, New York, NY, USA, 1980.

[32] P. Kaur, R. Verma, and N. C. Mahanti, "Selection of vendor using analytical hierarchy process based on fuzzy preference programming," OPSEARCH, vol. 47, no. 1, pp. 16-34, 2010. 


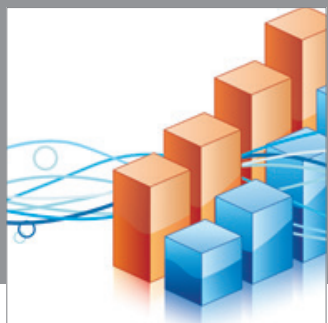

Advances in

Operations Research

mansans

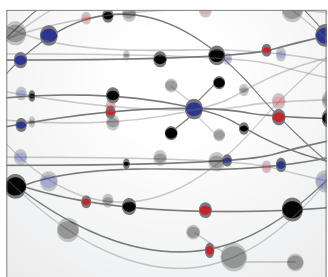

The Scientific World Journal
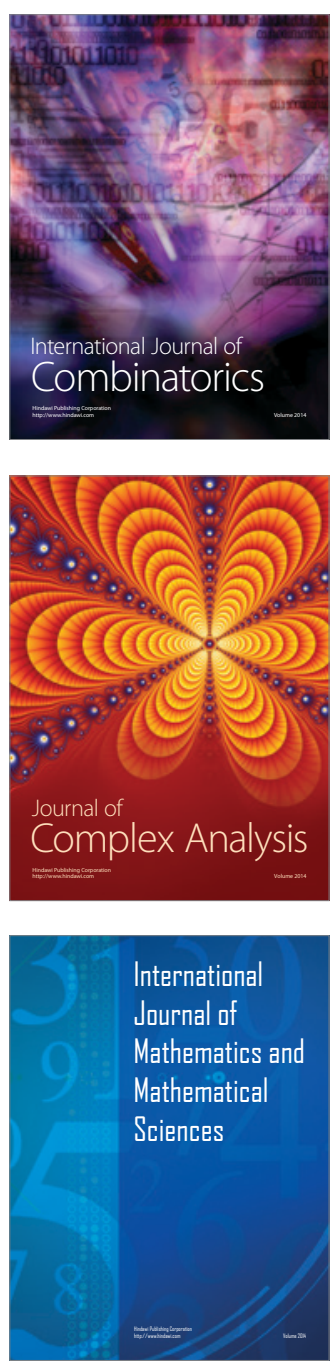
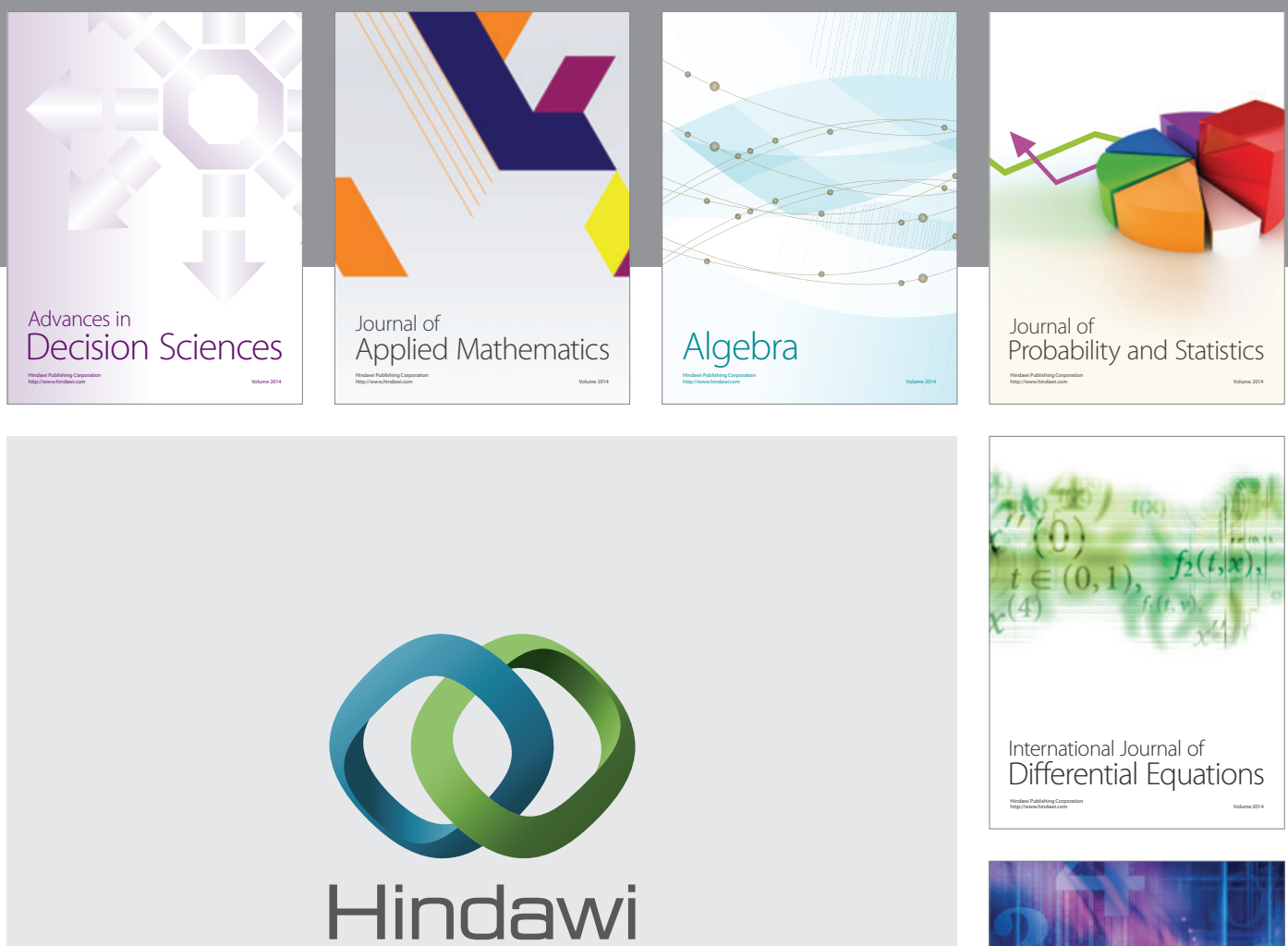

Submit your manuscripts at http://www.hindawi.com
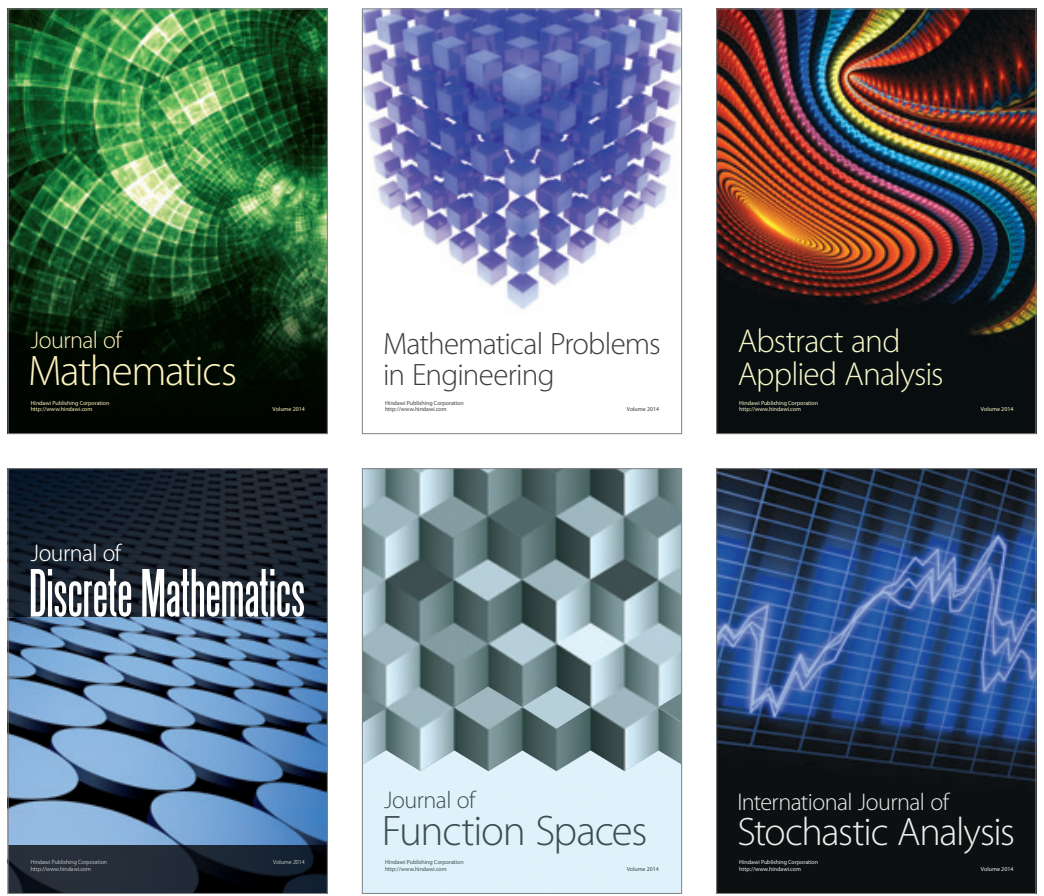

Journal of

Function Spaces

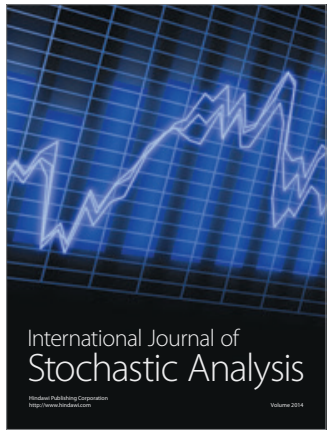

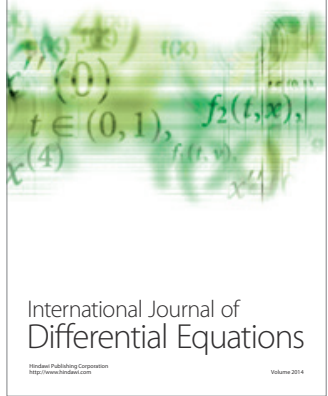
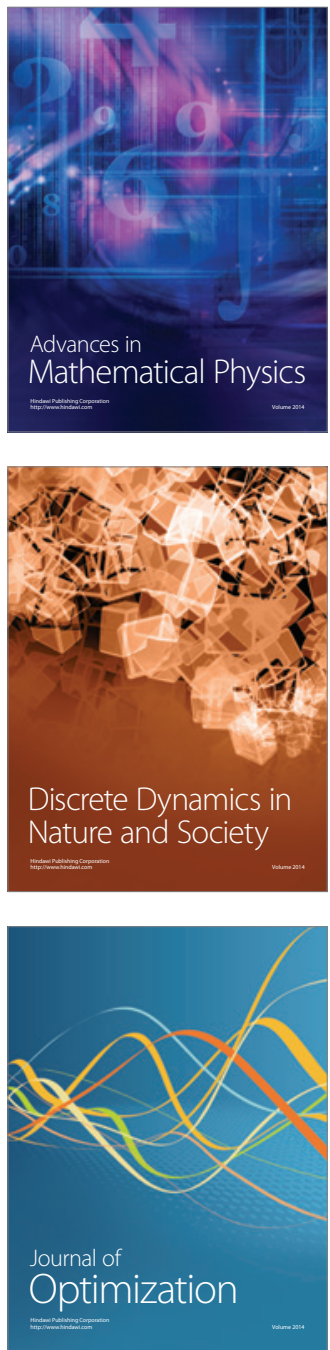